\title{
Effect of raising method of calves during liquid milk nutrition on their open-field and maze behaviour after weaning
}

\author{
Jan Broucek $^{a *}$ (D) | Michal Uhrincat ${ }^{\text {a }}{ }^{\text {iD }} \mid$ Peter Kisac ${ }^{a}$ | Anton Hanus ${ }^{a}$
}

${ }^{a}$ National Agricultural and Food Centre, Research Institute of Animal Production Nitra, Hlohovecka 2, 95141 Luzianky, Slovakia.

Corresponding author: jan.broucek@nppc.sk

\begin{abstract}
The objective was to find whether calf behaviour is affected by it rearing to weaning in 84 days, gender, and the sire lineage. 99 Holstein calves were assigned to 1 of 3 treatments: artificially reared in hutches (A), suckling of a foster cow (F), or suckling of the mother (M). After weaning (84 days), all calves were kept separately by sex in age-balanced groups. The speed of traversing the maze was recorded at 6 months of age. The open-field observation was performed at 10 months. The average time of traversing the maze facility was no significantly different among treatment groups. The average time of traversing the maze for 6 tasks was the highest in $A$ and the lowest in the F group $(P>0.05)$. At the openfield test, the difference compared to the grid (square) crossings was significant at the 1st minute of the 1 st test $(P<0.05)$. The average of the grid crossings in all tests was highest in $\mathrm{M}(139.5)$ and the lowest in $\mathrm{A}(123.1)(P>0.05)$. There were no significant differences between sex in behaviour in the maze or the open field tests. Sire lineage significant effect was found in vocalisation and defecation behaviour. The results show that the method used to rear calves and sire lineage may have an impact on their later behaviour.
\end{abstract}

Keywords dairy cattle, behaviour, maze, open-field test, weaning

\section{Introduction}

Calves artificially reared are separated from the mother within 24 hours after birth, housed individually in hutches, and fed by the milk replacer (MR) (Albright and Arave 1997; Davis and Drackley 1998; Novak et al 2019). Apart from immediate welfare problems, the early separation of dam and calf is likely to have negative implications on the health, e.g. poor udder health, endemic calf diseases, high susceptibility to stress and disease, and instability of social structures in the herd (Albright and Arave 1997; Broom and Fraser 1997).

The suckling systems can be broken down into multiple parts (Krohn 2001). The foster suckling system (also called Cow-calf contact system) means that 2-4 calves are kept together and suckle one foster cow (Albright and Arave 1997; Loberg and Lidfors 2001; Ellingsen et al 2016). The restricted suckling system implies that the calf is allowed to suckle its mother during short periods daily, for $2 \times 15$ or $2 \times$ 30 min (Fröberg et al 2007, 2008; de Passillé et al 2008; Roth et al 2009; Johnsen et al 2016). The suckling systems offered increased opportunities for natural behaviour, calf-cow bonding, and physiological drinking of milk (Wagenaar and Langhout 2007; Gygax and Hillmann 2018; Oliviera et al 2020).

It is accepted that the early behavioural developmental period in calves is of crucial importance for the stress-sensitivity of the animal in its later life. The poor rearing conditions in modern husbandry production systems, therefore, lay a foundation for the sensitivity to welfare problems that are experienced in adult animals (Albright and Arave 1997; Hagen and Broom 2004; Broom and Fraser 2007).

Dairy cattle need to develop behavioural flexibility to successfully cope with the stressors and changing environments they will encounter over their lifetime. It allows the individual animal to adapt behaviourally to changes in its environment (Wechsler and Lea 2007; Manteuffel et al 2009a; Grandin and Deesing 2014; Broucek et al 2017; Daigle et al 2020). Dairy cattle must be learning to operate feeders, drinkers, or visits of an automatic milking system (Fraser and Broom 1997; Broom and Fraser 2007; Broucek and Tongel 2015; Horvath et al 2017).

Multiple tests have been developed to evaluate cattle behaviour (e.g., labyrinth test, open field test), but each of these tests evaluates the animal's response to different stimuli (Forkman et al 2007; Daigle et al 2020). The maze learning ability is a type of operating conditioning and can be called trial-and-error learning or instrumental learning. The behaviour is the instrument by which the reinforcement is obtained (Houpt 1991; Kilgour 1981). Cattle can learn to traverse a maze when they are provided with step-by-step learning opportunities (Wredle et al 2004; Hirata et al 2016). Open-field tests are a method recommended to evaluate the temperament in animals and their ability to adapt to new unknown conditions (Kilgour 1975; Manteca and Dough 1993; Forkman et al 2007; Broucek et al 2011). 
The objective was to find whether dairy calves behaviours are affected by rearing to weaning in 84 days, gender, and the sire lineage.

\section{Materials and Methods}

\subsection{Animals and treatments}

The treatment of the animals was approved by the Ministry of Agriculture and Rural Development of the Slovak Republic, no. 115/1995 Z.z. and 377/2012 Z.z. The experiments were carried out in accordance with the Code of Ethics of the EU Directive 2010/63/EU for animal experiments and were performed according to the ethical guidelines and regulations set forth by National Agricultural and Food Centre, Research Institute for Animal Production Nitra/Ethical Commission, Hlohovecka 2, Luzianky, Slovakia.

At the birth, 99 Holstein calves (53 males and 52 females, descended from 4 sires) were randomly assigned to one of three rearing treatments. From each of the three males and each of the three females, one calf was randomly selected into the appropriate treatment group.

Group A, n=35, 18 males, 17 females, after having nursed their dams in individual pen for $24 \mathrm{~h}$ in hutches from 2nd to 56th day (bucket with nipple, MR, 2nd day $3 \times 0.5 \mathrm{~kg}$, 3 rd day $3 \times 1.0 \mathrm{~kg}$, 4 th day $3 \times 1.5 \mathrm{~kg}$, from 5 th day $6 \mathrm{~kg} / \mathrm{day}$, to 21st day $3 x$ daily), then loose housing pen to weaning from 57th day (bucket with nipple, MR, $6 \mathrm{~kg} /$ day, $2 x$ daily).

Group F, n=34, 17 males, 17 females, after 3 days with own mother in individual pen, then pen with non-milked cows from 4th day, calves could suckle at any time. The number of calves per nursing cow was determined according to milk yield of selected cows. Requirement $6 \mathrm{~kg}$ of milk per calf and day was available.

Group M, n=36, 18 males, 18 females, separately in a common individual pen with mother (milked from 2nd day) to 21st day, suckled a mother's udder 10 minutes 3 times per day, then group pen from the $22^{\text {nd }}$ day ( $6 \mathrm{~kg}$ milk per day, $2 \mathrm{x}$ daily, bucket with nipple).

Experimental calves originated from four sires (S1, S2, S3, and S4). The distribution was as follows: $A(S 1=5, S 2=9$, $\mathrm{S} 3=12, \mathrm{~S} 4=9) ; \mathrm{F}(\mathrm{S} 1=3, \mathrm{~S} 2=10, \mathrm{~S} 3=15, \mathrm{~S} 4=6) ; \mathrm{M}(\mathrm{S} 1=8, \mathrm{~S} 2=5$, $\mathrm{S} 3=14, \mathrm{~S} 4=9)$. By gender, this represented: Males $(\mathrm{S} 1=9$, $\mathrm{S} 2=10, \mathrm{~S} 3=20, \mathrm{~S} 4=14)$; Females $(\mathrm{S} 1=7, \mathrm{~S} 2=14, \mathrm{~S} 3=21, \mathrm{~S} 4=10)$.

All calves were weaned abruptly at the age of 12 weeks and moved to group housing pen, where equal conditions of nutrition were ensured. The transfer was made at the exact age of 84 days. Live body weight (LBW) of the calves was recorded at birth. All calves were weighed every week and then every month after weaning. The calves were weighed on the plate scale with LCD (Soehnle, Germany), load capacity up to $1000 \mathrm{~kg}$, weighing accuracy +/- $0.1 \mathrm{~kg}$.

\subsection{Feeding and health control}

From the 2nd day until weaning the calves were offered starter concentrate mixture (SCM) and alfalfa hay ad libitum. All calves offered the same SCM and forage.
After weaning, calves were fed alfalfa hay and corn silage ad libitum and $1.5 \mathrm{~kg} /$ day of concentrate mixture (CM). From 181 days, the males and females were fed the same total mixed feed ration throughout the study. The CM (1.5 $\mathrm{kg} /$ day) was fed separately. Drinking water was available at all times throughout the study. The methods of Slavik et al (2009) and Novak et al (2010) for the evaluation of the health were used.

\subsection{Housing}

Hutches (group A) were made from fibre-glass (white colour), used from the second day of life to relocation to group housing at the age of 8 weeks. Each hutch $(1.8 \times 1.2 \mathrm{~m})$ had an outside fenced yard of $1.8 \times 1.2 \mathrm{~m}$, bedded with straw. Hutches were arranged in rows, $0.8 \mathrm{~m}$ apart. Group $\mathrm{F}$ was housed in a pen of $9 \times 4.5 \mathrm{~m}$ ( 3 nursing cows and $10-12$ calves). Cows were tied in the pen, calves loose. Calves received SCM and alfalfa hay separately. Group $M$ was kept in individual pens of $4.5 \times 4.5 \mathrm{~m}$, one cow, one calf. A small part of the pen was separated for calf $(1.2 \times 4.5)$.

After weaning from milk feeding, all calves were kept sex separately in age-balanced groups in loose housing bedded pens with the same feed ration. Approximately 10 15 calves were kept in a pen of $9 \times 4.5 \mathrm{~m}$. Each treatment group had its pens for males and females, also pens differentiated by age. The principle was observed that the age difference in one pen was not higher than 21 days. The calves of A group could see and touch each other through the openings in the upper part of the pen wall or fenced yard of the hutch. The calves had no visual contact with the mother (M group) or foster cow (F group), only acoustic. Each calf had free access to clean drinking water in a plastic bucket or automatic drinker throughout the study.

\subsection{Behaviour}

\subsubsection{Maze}

Learning ability was evaluated at the age of 6 months of life by the Hebb-Williams test. The closed field maze was constructed in an $8 \times 14 \mathrm{~m}$ room. Problem tasks were constructed using $2 \mathrm{~m}$ high plywood barriers. The path of the cow through the maze task was recorded by video. Calves solved six tasks for three days. Tasks 1 and 2 used a left-side solution, 3 and 4 a right-side solution, and 5 and 6 a central solution (Kilgour 1981). Odd-numbered tasks were in visual form, while even-numbered problems were non-visual. The motivation to finish the problem was access to a concentrated mixture at the exit. Each task was performed twice (two runs). The speed of traversing the maze and the time of standing in the maze were recorded.

The calf was put into the maze entrance and a door closed behind it. The animal was timed from when it entered the maze until it got out. If the calf stood without movement in the enter part for more than 3 minutes, it was forced gently to movement. If the calf stood without movement more than 3 minutes in the rear part of the maze, it was taken out. The calf was allowed to CM eating for only a few seconds, 
whereupon it was lead out of the maze. On the first observation day the calves completed five runs, the first run was for training.

\subsubsection{Open-field}

Bulls and heifers were individually tested in the 10th month of life in a $10 \times 10 \mathrm{~m}$ arena marked off into 9 squares. Tests are $5 \mathrm{~min}$. long and repeated two times daily during 2 consecutive days. Arena had a concrete floor and was visually and acoustically isolated from other animals. After testing of each calf, the arena was carefully cleaning by flushing of water. The numbers of crossed squares (also called grid crossings), vocalizations, defecations, and urinations were recorded.

Behavioural data were obtained by video observations and electronic measurements. The room of the maze and arena for open-field tests were equipped with video cameras for continuous filming of the cows' activities. There were computer technics and software for evaluation (cameras Samsung SCB-3000P, HDD recorder Versatile H.264 DVR), and the Observer $\mathrm{XT}$, Noldus (software on transmitting behavioural activities into numerical data).

\subsection{Statistical analyses}

The data were analysed using a general linear model ANOVA (AOV/AOCV) by the statistical package STATISTIX, Version 10.0. The dependent variables were times maze traversing and standing, number of square crossings, vocalizations, and defecations. The independent variables were treatment group $(T)$, gender $(G)$, and sire lineage $(S)$.

The normality of data distribution was evaluated by the Wilk-Shapiro/Rankin Plot procedure. All the behavioural parameters were normally distributed and no relevant outliers appeared. The homogeneity of variance of the observed variables in groups was calculated by preliminary variance tests which determined whether the variabilities were equal. Bartlett's test for the equality of variance tests was used for an unequal size of samples. Differences between groups were tested by Comparisons of Mean Ranks. Significant differences among means were tested by Bonferroni's test.

All values are reported as means \pm standard deviation. The interactions between observed factors (treatment, gender, and sire lineage) were also computed. The following model of General AOV/AOCV on observed factors (treatment and sire lineage) was used:

$$
Y i j k=\mu+T i+G j+S k+\alpha i j+\beta i k+\gamma j k+\varepsilon i j k
$$

where Yijk is a dependent variable, $\mu$ is the overall mean, $T i$ is the effect of factor treatment on the level $i, G j$ is the effect of factor gender on the level $j$, Sk is the effect of factor sire lineage on the level $k$, $\alpha i j$ is the interaction between factor $T$ on the level $i$ and factor $G$ on the level $j$, $\beta i k$ is the interaction between factor $T$ on the level $i$ and factor $S$ on the level $k, j j$ is the interaction between factor $G$ on the level $j$ and factor $S$ on the level $k$, and $\varepsilon i j k$ is the residual error.

\section{Results}

The results from the maze learning ability are shown in Table 1. There were no significant effects of treatment, gender or sire lineage on calves' behaviour. The average time of traversing the maze for 6 tasks was the highest in A group $(1582.4 \pm 346.55 \mathrm{~s})$ and the lowest in F group $(1455 \pm 862 \mathrm{~s} ; P>$ $0.05)$. Similarly, the time of standing in the maze was a tendency for the A group increasing (948.34 $\pm 346.89 \mathrm{~s}$, 862.71 \pm 384.65 s, $873.76 \pm 411.97 \mathrm{~s} ; P>0.05)$.

Table 1 The maze behaviour for all tests.

\begin{tabular}{|c|c|c|c|c|c|c|}
\hline \multirow[t]{2}{*}{ Group } & & \multirow[t]{2}{*}{ Mean } & \multirow[t]{2}{*}{ SD } & \multicolumn{3}{|c|}{ Treatment factor } \\
\hline & & & & Group & Sex & Sire \\
\hline \multicolumn{7}{|c|}{ Times maze traversing } \\
\hline A & 36 & 1582.4 & 346.55 & & & \\
\hline $\mathrm{F}$ & 34 & 1455.5 & 419.43 & NS & NS & NS \\
\hline$M$ & 35 & 1466.4 & 418.67 & & & \\
\hline \multicolumn{7}{|c|}{ Times maze standing } \\
\hline A & 36 & 948.34 & 346.89 & & & \\
\hline $\mathrm{F}$ & 34 & 862.71 & 384.65 & NS & NS & NS \\
\hline$M$ & 35 & 873.76 & 411.97 & & & \\
\hline
\end{tabular}

At the observation of the open-field test, the difference compared to the grid crossings was significant at the 1st minute of the 1st test (A 7.12 $\pm 2.88 ; \mathrm{F} 9.12 \pm 3.48, \mathrm{M}$ $9.24 \pm 4.17 ; P<0.05$ ) (Table 2). The average of the grid crossings in all tests was tended to be highest in $\mathrm{M}$ and the lowest in A (A 123.06 $\pm 57.71, F$ 136.68 $\pm 36.31, M$ $139.55 \pm 42.18 ; \quad P>0.05)$. There were no significant differences between sex and sire.

The highest number of vocalisations at the first minute of the $1^{\text {st }}$ test was recorded in group $M$ and the lowest in 
group A (A 2.59 \pm 3.09, F 3.41 \pm 3.34, M 4.79 $\pm 4.36, P<0.05$ ) (Table 3 ). The same significant trend was found for the total number of vocalisations (A 20.28 $\pm 19.07, F 24.44 \pm 19.43$, M $30.03 \pm 20.83, P<0.05)$. No significant differences were found in gender comparison. Calves after father $\mathrm{S} 1$ had the lowest vocalisations number and calves descended of sire S2 the highest at the first minute (S1 2.42 \pm 3.03 , S2 4.45 \pm 4.12 , S3 $4.02 \pm 4.01$, S4 2.83 $\pm 2.98 ; P<0.05$ ) and for all first test (S1

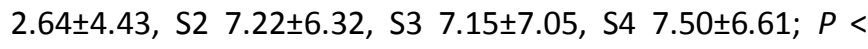
$0.05)$.

The defecation numbers during the first minute of the $1^{\text {st }}$ test and for all tests were statistically different (Table 4).
The lowest number of defecations was identically recorded in group $A$ and the highest number was found in group $F$ ( $A$ $0.42 \pm 0.38$, F 0.87 \pm 0.44 ; A 3.41 \pm 3.50 , F 5.12 $\pm 2.67 ; P<0.05$ ). The significant difference was determined among the sire lineages at the first test (S1 2.00 \pm 1.30 , S2 $1.59 \pm 1.09$, S3 $1.10 \pm 1.09$, S4 1.21 $\pm 1.14 ; P<0.05)$.

There were no significant effects of treatment, gender or sire lineage on calf's urination. We did not found any significant interactions among calculated factors, except for an interaction between Sex and Sire lineage in Test $1(P<$ 0.01).

Table 2 Grid crossings number.

\begin{tabular}{|c|c|c|c|c|c|c|}
\hline \multirow[t]{2}{*}{ Group } & \multirow[t]{2}{*}{$\mathrm{N}$} & \multirow[t]{2}{*}{ Mean } & \multirow[t]{2}{*}{ SD } & \multicolumn{3}{|c|}{ Treatment factor } \\
\hline & & & & Group & Sex & Sire \\
\hline \multicolumn{7}{|c|}{ 1st minute of 1 st test } \\
\hline A & 34 & 7.12 & 2.88 & & & \\
\hline $\mathrm{F}$ & 32 & 9.12 & 3.48 & $0.0487^{*}$ & NS & NS \\
\hline$M$ & 35 & 9.24 & 4.17 & $\mathrm{~A}: \mathrm{M}, \mathrm{F}^{*}$ & & \\
\hline \multicolumn{7}{|c|}{ Test 1} \\
\hline A & 34 & 33.66 & 12.48 & & & \\
\hline $\mathrm{F}$ & 32 & 33.50 & 10.62 & NS & NS & NS \\
\hline $\mathrm{M}$ & 35 & 34.36 & 9.15 & & & \\
\hline \multicolumn{7}{|c|}{ Total for all tests } \\
\hline A & 34 & 123.06 & 57.71 & & & \\
\hline $\mathrm{F}$ & 32 & 136.68 & 36.31 & NS & NS & NS \\
\hline$M$ & 35 & 139.55 & 42.18 & & & \\
\hline
\end{tabular}

Table 3 Vocalisations number.

\begin{tabular}{|c|c|c|c|c|c|c|}
\hline \multirow[t]{2}{*}{ Group } & \multirow[t]{2}{*}{$\mathrm{N}$} & \multirow[t]{2}{*}{ Mean } & \multirow[t]{2}{*}{ SD } & \multicolumn{3}{|c|}{ Treatment factor } \\
\hline & & & & Group & Sex & Sire \\
\hline \multicolumn{7}{|c|}{ 1st minute of 1 st test } \\
\hline A & 34 & 2.59 & 3.09 & & & \\
\hline $\mathrm{F}$ & 32 & 3.41 & 3.34 & $0.0226 *$ & NS & $0.0488^{*}$ \\
\hline $\mathrm{M}$ & 35 & 4.79 & 4.36 & $\mathrm{~A}: \mathrm{M}^{*}$ & & $\mathrm{~S} 1: \mathrm{S} 2 *$ \\
\hline \multicolumn{7}{|c|}{ Test 1} \\
\hline A & 34 & 5.72 & 6.23 & & & \\
\hline $\mathrm{F}$ & 32 & 6.20 & 6.33 & NS & NS & $0.0498^{*}$ \\
\hline$M$ & 35 & 7.91 & 7.15 & & & $\mathrm{~S} 1: \mathrm{S} 2 *$ \\
\hline \multicolumn{7}{|c|}{ Total for all tests } \\
\hline A & 34 & 20.28 & 19.07 & & & \\
\hline $\mathrm{F}$ & 32 & 24.44 & 19.43 & 0.0496* & NS & NS \\
\hline$M$ & 35 & 30.03 & 20.83 & $A: M^{*}$ & & \\
\hline
\end{tabular}

\section{Discussion}

\subsection{Maze behaviour}

In recent years, farm animals have been increasingly used in experiments on maze or spatial learning. It was showed that dairy cattle can learn from difficult tasks (Wechsler and Lea 2007; Manteufel et al 2009 b; Lauber et al 2009). According to Hirata et al (2016), cows can learn to traverse a maze when they are provided with a gradual increase in the difficulty of learning opportunities.

We did not find significant differences in the time of traversing the maze among treatments, but the tendency was clear. Calves from group $F$ solved the problems the fastest, and this was evident in all the tests. The slowest passage through the maze was found in group A calves. These results suggest that providing enrichment in the form of a foster teat during the milk feeding period can change calf's 
behaviour responses in ethological tests. Calves of $\mathrm{F}$ group took less time to find the reward during the learning tasks. Calves housed in unenriched environments $(A)$ or enriched environment for 21 days only (M) had reduced flexibility in maze tasks.

However, Horvath et al (2017) found that allowing calves to diversify the environment during the liquid feeding period reduced their reactivity to a novel object placed in the maze. Therefore, we must recall that their environment enrichment concerned offering hay and artificial teat and that is something different than in the present experiment. Also, it is well known that temperament may affect learning in calves, but only weak relationships were found between temperament and learning traits (Webb et al 2015). However, we did not evaluate temperament in the presented work.
Purcell and Arave (1992) studied the effect of early rearing experience on behaviour. They found that preweaning isolation affected learning ability. Also, at the studies of Gaillard et al (2014) and Meagher et al (2015), the individually housed calves had learning deficits versus paired and grouped calves. We assume that calves raised in individual hutches, that is, in isolation and with limited movement (A) cannot sufficiently express their social behaviour; they cannot quickly cope with the new situation, and therefore have impaired learning abilities. These results confirm the previous findings of authors Costa et al (2016). However, it was also noted that being in a group impaired the occurrence of active adaptive strategies (Veissier and Le Neindre 1992).

Table 4 Defecations number.

\begin{tabular}{|c|c|c|c|c|c|c|}
\hline \multirow[t]{2}{*}{ Group } & \multirow[t]{2}{*}{$\mathrm{N}$} & \multirow[t]{2}{*}{ Mean } & \multirow[t]{2}{*}{ SD } & \multicolumn{3}{|c|}{ Treatment factor } \\
\hline & & & & Group & Sex & Sire \\
\hline \multicolumn{7}{|c|}{ 1st minute of 1st test } \\
\hline$A$ & 34 & 0.42 & 0.38 & & & \\
\hline $\mathrm{F}$ & 32 & 0.87 & 0.44 & $0.0491^{*}$ & NS & NS \\
\hline$M$ & 35 & 0.67 & 0.41 & $\mathrm{~A}: \mathrm{F}^{*}$ & & \\
\hline \multicolumn{7}{|c|}{ Test 1} \\
\hline$A$ & 34 & 1.12 & 1.29 & & & \\
\hline $\mathrm{F}$ & 32 & 1.53 & 1.05 & NS & NS & $0.0462^{*}$ \\
\hline $\mathrm{M}$ & 35 & 1.42 & 1.14 & & & \\
\hline \multicolumn{7}{|c|}{ Total for all tests } \\
\hline$A$ & 34 & 3.41 & 3.50 & & & \\
\hline $\mathrm{F}$ & 32 & 5.12 & 2.67 & 0.0499* & NS & NS \\
\hline$M$ & 35 & 4.15 & 2.87 & A:F* & & \\
\hline
\end{tabular}

The reason for our insignificant differences between groups may also be the increased variability. Horvath and Miller-Cushon (2018) suggest that individual variability in Tmaze tasks may be predictive of behavioural responses and the ability to adapt to a novel environment.

The present experiment showed that neither gender nor sire lineage significantly affected the times of running across the maze and standing in the maze. But, heifers were faster in running a maze (1488 s versus $1511 \mathrm{~s}$, for all six tests) than bulls. It is not different compared to Stewart et al (1992). Also, Arave et al (1992) proved that male calves were slower to find the food reward than females. Holstein heifers of some sires showed a better ability to learn in the maze.

\subsection{Open-field behaviour}

\subsubsection{Locomotion}

The group A moved the least in the open-field arena, on the contrary, both suckling groups $\mathrm{F}$ and $\mathrm{M}$ differed only minimally in the movement measured by the transitions of squares ( 136.7 versus 139.5 squares). This may point out that suckling milk from foster cow and mother or loose housing may alter calf locomotor responses to the unknown arena of the open-field. Providing social enrichment in the form of housing with foster (to weaning) or with mother (to 21 days) makes calves less fearful in novel social and environmental situations than individually-housed calves (A). Calves from group housing pens certainly adapt faster to unfamiliar environments when they are repeatedly let into the openfield test arena than individually housed calves (Gaillard et al 2014), and they are faster to touch novel objects (Meagher et al 2016). Suckling was found to influence the levels of reactivity: compared to weaned heifers, suckling heifers reacted more to the feed after fear conditioning (Veissier et al 1987). Housing calves in groups allows them to perform their natural social behaviour, provides more space for play and general activity which improves their welfare (Vaughan 2014).

Other authors (Jensen and Larsen 2014; Marino and Allen 2017) show that calves housed individually are more fearful of unfamiliar calves than are pair-housed calves. However, de Paula Vieira et al (2012) noted that individually reared calves are more reactive, and spend much more time exploring the unknown space than pair housed calves. In cattle, enhanced locomotor activity is an indicator of stress (Juhas and Debreceni 1998) and reduced locomotion can be an indicator of fearfulness (Van Reenen et al 2005). 
According to de Passillé et al (1995), Keyserlingk von et al (2009) and Mackay et al (2014), frightening, in particular, is an important negative trait. At the present work, the method of rearing using a foster cow or own mother could be the cause of excitement in an isolated area of the arena, which manifested itself in intense movement. These two groups of calves had formed a bond with adult cows during the milk feeding stage, and they were probably less independent than calves from artificial rearing in hutches.

Calves reared in smaller pens show more locomotor play when released into a larger open area (Dellmeier et al 1985, 1990; Jensen and Kyhn 2000; Jensen et al 2004; Rushen and de Passillé 2014). Behaviour in the open field reflects several motivations (de Passillé et al., 1995). Increased locomotion after a period of restriction may indicate an internal motivation to perform that behaviour during the period of restriction (Dellmeier et al 1990; Jensen et al 1999b; Sutherland et al 2014). However, Wagner et al (2013) found that mother-reared calves with unrestricted contact with the cowherd had less frequently locomotor play than artificially reared calves fed milk via an automatic milk feeder.

Locomotor behaviour in the open-field test did not differ either between sex groups or among the observed sires. However, we may not have made a precise distinction between the kind of motivation in cattle which is expressed by locomotor behaviour: fear, exploration, or social motivation.

The present study was no significant differences among the sex factor. However, heifers were more mobile in the open-field facility. They crossed more squares than bulls (136.3 versus 129.8 ). Also in other open-field test variables manifested themselves differently compared to bulls.

\subsubsection{Vocalisation and defecation}

Calves $\mathrm{M}$ group mooed the most and calves $\mathrm{A}$ group vocalised the least. Significant differences were recorded at the first minute of the first test and in the total value for all 4 tests. It is difficult to explain this phenomenon. According to the authors of the present study, this may be similar to the previous variable, the number of crossed squares. The highest number was found in group $M$ and the lowest in group $A$. The reason is probably the restrictive suckling of mothers (only $3 x$ daily) when calves waited for their milk dose and vocalised impatiently and eagerly (de la Torre et al 2016). We must also mention again an important negative feature, namely independence. Also, it is likely that the vocal response emphasising how cattle have a level of habituation to social isolation (Juhas et al 2001; Mueller and Schrader 2005; Siebert et al 2011; Green et al 2018) and may be a useful indicator of their physiological and psychological functioning (Watts and Stookey 2000).

The vocalisation of calves during open-field tests can be a response to separation and it expresses acute stress or an unpleasant treatment (Lidfors 1996; Flower and Weary 2001, Watts and Stookey 2001; Stehulova et al 2008; Rhim 2013). Vocalisation behaviour increases with longer contact with the mother from birth (Johnsen et al 2015; Stehulova et al 2017; Steele 2019). The inclination of a calf to vocalise is impacted by time of separation from its mother or foster cow (21 days or 84 days). This may apply to group $M$ from the present study. Cattle also vocalize more frequently when visually isolated from companions (Boissy and Le Neindre 1997).

No significant differences were found in gender comparison. But, heifers had a higher frequency of mooings for all four tests (6.8 versus 6.4). Watts and Stookey (200l) reported that the vocal responses of cattle to visual isolation are influenced by genetic factors. This variability imposes some limitations on how vocal response should be used in welfare measurement. At the current study, calves after father S1 had the lowest vocalisations number and calves descended of sire S2 the highest at the first minute and for the whole first test. Differences were significant.

Cattle are known to defecate and urinate in response to stressful situations (Friend 1991). The elimination behaviour may be a result of arousal without necessarily indicating an emotional response (Lauber et al 2006; Vaughan 2014). Group A calves defecated the least and group $F$ calves the most in the open-field arena. This was most pronounced in the first minute of the first test and the total value for all 4 tests. It could have caused by the animal's fear and uncertainty. Certainly, these two variables are closely related. Similar results noted Albright and Arave (1997). Calves, those reared in groups being alone for the first time, urinated and defecated more than calves reared in isolation. Our present results are in contrast to the findings of de PaulaVieira et al (2012). They recorded that individually reared calves defecated more than pair kept calves.

Heifers had higher frequency defecations for all four tests (4.5 versus 4.0). The significant difference was determined among the sire lineages at the first test, the highest number of defecations had calves after S1 and the lowest offspring of the bull S3. There were no significant effects of treatment, gender or sire lineage on calf's urination.

\section{Conclusions}

The main purpose of this study was that providing calves with different feeding and housing to weaning would change their success in a maze test and reactivity to novel stimuli in the open-field test.

In the evaluation of the entire maze test, groups $F$ (suckling of foster cows) appears to be the most adaptable, and calves from group A (hutches) the least adaptable.

At the open-field test, the difference compared to the grid crossings was significant at the 1st minute of the 1st test. The average of the grid crossings in all tests was highest in $M$ (suckling of the mother) and the lowest in A. There were no significant differences between sex groups in the maze behaviour or locomotion in the open field tests. A sire-lineage significant effect was found only in vocalisation and defecation behaviour. The results show that the method used to rear calves may have an impact on their later behaviour. 


\section{Conflict of Interest}

The authors declare that they have no conflict of interest.

\section{Funding}

This article was written based on data projects APVV-15-0060 of the SRDA, Slovakia, and Sustainable Smart Farming Systems 313011 W112 of the OPII supported by the European Regional Development Fund.

\section{References}

Albright JL, Arave CW (1997) The Behaviour of Cattle. CAB International. Appleby MC, Hughes BO (1997) Animal Welfare. CAB International.

Arave CW, Lamb RC, Arambel MJ, Purcell D, Walters JL (1992) Behaviour and maze learning ability of dairy calves as influenced by housing, sex and sire. Applied Animal Behaviour Science 33:149-163.

Boissy A (1995) Fear and fearfulness in animals. The Quarterly Review of Biology 70:165-191.

Boissy A, Le Neindre P (1997) Behavioral, cardiac and cortisol responses to brief peer separation and reunion in cattle. Physiology \& Behavior 61:693699.

Broom DM, Fraser AF (2007) Domestic Animal Behaviour and Welfare. CAB International.

Broucek J, Uhrincat M, Hanus A (2011) Learning and locomotor behaviour study of dairy calves kept in group housing. Slovak Journal of Animal Science 44:72-77.

Broucek J, Tongel P (2015) Adaptability of dairy cows to robotic milking: a review. Slovak Journal of Animal Science 48:86-95.

Broucek J, Uhrincat M, Mihina S, Soch M, Mrekajova A, Hanus A (2017) Dairy Cows Produce Less Milk and Modify Their Behaviour during the Transition between Tie-Stall to Free-Stall. Animals 7: 16; doi:10.3390/ani7030016.

Costa JHC, von Keyserlingk MAG, Weary DM (2016) Effects of group housing of dairy calves on behavior, cognition, performance, and health. Journal of Dairy Science 99:2453-2467.

Daigle CL, Hubbard AJ, Grandin T (2020) The Use of Traditional Fear Tests to Evaluate Different Emotional Circuits in Cattle. Journal of Visualized Experiments 158:e60641. doi:10.3791/60641

Davis CL, Drackley JK (1998) The development, nutrition, and management of the young calf. lowa University Press, Ames.

de la Torre MP, Briefer EF, Ochocki BM, McElligott AG, Reader T (2016) Mother offspring recognition via contact calls in cattle, Bos taurus. Animal Behaviour 114:147-154.

de Oliveira D, Barth K, Haskell MJ, Hillmann E, Jensen MB, Johnsen JF, Mejdell C, Waiblinger S, Ferneborg S (2020) Methodology for experimental and observational animal studies in cow-calf contact systems. Journal of Dairy Research 87:115-121.

de Passillé AM, RushenJ., Martin F (1995) Interpreting the behaviour of calves in an open-field test: a factor analysis. Applied Animal Behaviour Science 45:201-213.

de Passillé AM, Marnet PG, Lapierre H, Rushen J (2008) Effects of twice-daily nursing on milk ejection and milk yield during nursing and milking in dairy cows. Journal of Dairy Science 91:1416-1422.

De Paula Vieira A, de Passillé AM, Weary DM (2012) Effects of the early social environment on behavioral responses of dairy calves to novel events. Journal of Dairy Science 95:5149-5155.

Dellemeier GR, Friend TH, Gbur EE (1985) Comparison of four methods of calf confinement. II. Behaviour. Journal of Animal Science 60:1102-1109.

Dellemeier GR, Friend TH, Gbur EE (1990) Effects of changing housing on open-field behavior of calves. Applied Animal Behaviour Science 26:215-230.

Ellingsen K, Mejdell CM, Ottesen N, Larsen S, Grøndahl AM. 2016. The effect of large milk meals on digestive physiology and behaviour in dairy calves. Physiology \& Behavior 154:169-174.
Flower FC, Weary DM (2001) Effects of early separation on the dairy cow and calf: 2 . separation at 1 day and 2 weeks after birth. Applied Animal Behaviour Science 70:275-284.

Forkman B, Boissy A, Salaün MC, Canali E, Jones RB (2007) A critical review of fear tests used on cattle, pigs, sheep, poultry and horses. Physiology \& Behavior 92:340-374.

Fraser AF, Broom DM (1990) Farm animal behaviour and welfare. CAB International.

Friend TH (1991) Behavioral aspects of stress; Journal of Dairy Science 74:292-303.

Fröberg S, Aspergen-Guldorff A, Olsson I, Marin B, Berg C, Hernandez C, Galina CS, Lidfors L, Svennersten-Sjaunja K (2007) Effect of restricted suckling on milk yield, milk composition and udder health in cows and behaviour and weight gain in calves, in dual-purpose cattle in the tropics. Tropical Animal Health and Production 39:71-81.

Fröberg S, Gratte E, Svennersten-Sjaunja K, Olsson I, Berg C, Orihuela A, Galina CS, Garcia B, Lidfors L (2008) Effect of suckling ('restricted suckling') on dairy cows' udder health and milk let-down and their calves' weight gain, feed intake and behaviour. Applied Animal Behaviour Science 113:1-14.

Gaillard C, Meagher RK, von Keyserlingk MAG, Weary DM (2014) Social housing improves dairy calves' performance in two cognitive tests. Plos One 9:e90205.

Grandin T, Deesing MJ (2014) Genetics and Behavior During Handling, Restraint, and Herding. In: Grandin T (ed) Genetics and the Behavior of Domestic Animals, 2nd edn. Academic Press, San Diego, pp 115-158.

Green AC, Johnston IN, Clark CEF (2018) Invited review: The evolution of cattle bioacoustics and application for advanced dairy systems. Animal 12:1250-1259. doi:10.1017/S1751731117002646

Gygax L, Hillmann E (2018) 'Naturalness' and its relation to animal welfare from an ethological perspective. Agriculture 8, 136 doi:10.3390/agriculture8090136

Hagen K, Broom DM (2004) Emotional reactions to learning in cattle. Applied Animal Behaviour Science 85:203-213.

Hirata M, Tomita C, Yamada K (2016) Use of a maze test to assess spatial learning and memory in cattle: Can cattle traverse a complex maze? Applied Animal Behaviour Science 180:18-25.

Horvath K, Fernandez M, Miller-Cushon EK (2017) The effect of feeding enrichment in the milk-feeding stage on the cognition of dairy calves in a Tmaze. Applied Animal Behaviour Science 187:8-14.

Horvath K, Miller-Cushon EK (2018) Characterizing social behavior, activity, and associations between cognition and behavior upon social grouping of weaned dairy calves. Journal of Dairy Science 101:7287-7296.

Houpt KA (1991) Domestic Animal Behavior for veterinarians and animal scientists. lowa State University Press, Ames.

Jensen MB (1999) Effects of confinement on rebounds of locomotor behaviour of calves and heifers, and the spatial preferences of calves. Applied Animal Behaviour Science 62:43-56.

Jensen MB, Kyhn R (2000) Play behaviour in group-housed dairy calves, the effect of space allowance. Applied Animal Behaviour Science 67:35-46.

Jensen MB, Tuomisto L, Pedersen LJ (2004) Locomotor behaviour in dairy calves, the use of demand functions to assess the effect of deprivation. Applied Animal Behaviour Science 86:3-14.

Jensen M B, Larsen LE (2014). Effects of level of social contact on dairy calf behavior and health. Journal of Dairy Science 97:5035-5044.

Johnsen JF, Passillé de AM, Mejdell CM, Boe KE, Grondahl AM, Beaver A, Rushen J, Weary DM (2015) The effect of nursing on the cow-calf bond. Applied Animal Behaviour Science 163:50-57.

Johnsen JF, Zipp KA, Kalber T, Passillé de AM, Knierim U, Barth K, Mejdell CM (2016) Is rearing calves with the dam a feasible option for dairy farms? Current and future research. Applied Animal Behaviour Science 181:1-11.

Juhas P, Debreceni O (1998) Behavioral disorders in cattle in different housing condition in Slovakia. In: Book of abstract of the 49th Annual Meeting of the European Association for Animal Production, Warsaw, 4:196. 
Juhas P, Debreceni O, Vavrisinova K, Bulla J, Strapak P (2001) Abnormal Behaviours in Cattle in Slovakia. Biotechnology in Animal Husbandry 17:113118.

Kilgour RJ (1975) The open-field test as an assessment of the temperament of dairy cows. Animal Behaviour 23:615-624.

Kilgour R (1981) Use of the Hebb-Williams closed-field test to study the learning ability of Jersey cows. Animal Behaviour 29:850-860.

Kilgour R (1987) Learning and the Training of Farm Animals. Veterinary Clinics of North America: Food Animal Practice, Farm Animal Behavior 3:269-284.

Krohn CC (2001) Effects of different suckling systems on milk production, udder health, reproduction, calf growth and some behavioural aspects in high producing dairy cows - a review. Applied Animal Behaviour Science 72:271-280

Lauber MCY, Hemsworth PH, Barnett JL (2006) The effects of age and experience on behavioural development in dairy calves. Applied Animal Behaviour Science 99:41-52.

Lauber MC, Hemsworth PH, Barnett JL (2009) The effect of breed, time spent with dam and late pregnancy induction of parturition on behavioural development in dairy calves. Behavioural Processes 82:301-311.

Lidfors LM (1996) Behavioural effects of separating the dairy calf immediately or 4 days post-partum. Applied Animal Behaviour Science 49:269-283.

Loberg J, Lidfors L (2001) Effect of stage of lactation and breed on dairy cows acceptance of foster calves. Applied Animal Behaviour Science 74:97-108.

MacKay JRD, Haskell MJ, Deag JM, van Reenen K (2014) Fear responses to novelty in testing environments are related to day-to-day activity in the home environment in dairy cattle. Applied Animal Behaviour Science 152:7 16.

Mala G, Novak P, Jiroutova P, Knizek J, Prochazka D, Slavikova M (2019) The effect of housing system on behaviour of dairy calves. Proceedings of the XIXth Congress International Society of Animal Hygiene, Wroclaw, Poland, pp 46-48.

Manteca X, Deag JM (1993) Individual differences in temperament of domestic animals: A review of methodology. Animal Welfare 2:247-268.

Manteuffel G, Langbein J, Puppe B (2009a) From operant learning to cognitive enrichment in farm animal housing: bases and applicability. Animal Welfare 18:87-95.

Manteuffel G, Langbein J, Puppe B (2009b) Increasing farm animal welfare by positively motivated instrumental behaviour. Applied Animal Behaviour Science 118:191-198.

Marino L, Allen K (2017) The psychology of cows. Animal Behavior and Cognition 4:474-498.

Meagher RK, Daros RR, Costa JHC, von Keyserlingk MAG, Hötzel MJ, Weary DM (2015) Effects of Degree and Timing of Social Housing on Reversa Learning and Response to Novel Objects in Dairy Calves. PLoS ONE 10 e0132828. doi: 10.1371/journal.pone.0132828

Meagher RK, von Keyserlingk MAG, Atkinson D, Weary DM (2016) Inconsistency in dairy calves' responses to tests of fearfulness. Applied Animal Behaviour Science 185:15-22.

Müller R, Schrader L (2005) Individual Consistency of Dairy Cows' Activity in Their Home Pen. Journal of Dairy Science 88:171-175.

Novak P, Vokralova J, Tittl K, Mala G, Illek J (2010) Selected aspects of welfare and prevention of disease in ruminants. Veterinarstvi 60:25-27.

Novak P, Mala G, Jarolimkova A. 2019. Animal, housing and nutrition as prerequisite for health, reproduction and production in dairy cattle. Proceedings of the XIXth Congress International Society of Animal Hygiene, Wroclaw, Poland, pp 49-51.

Purcell D Arave CW (1991) Isolation vs. group rearing in monozygous twin heifer calves. Applied Animal Behaviour Science 31:147-156.

Rhim SJ (2013) Vocalization and behavior of Holstein cows and calves after partial and complete separation. Revista Colombiana de Ciencias Pecuarias 26:24-29.

Roth BA, Barth K, Gygax L, Hillmann E (2009) Influence of artificial vs. motherbonded rearing on sucking behaviour, health and weight gain in calves. Applied Animal Behaviour Science 119:143-150.
Rushen J, de Passillé AMB (2014) Locomotor play of veal calves in an arena: Are effects of feed level and spatial restriction mediated by responses to novelty? Applied Animal Behaviour Science 155:34-41.

Siebert K, Langbein J, Schön PC, Tuchscherer A, Puppe B (2011) Degree of social isolation affects behavioural and vocal response patterns in dwarf goats (Capra hircus). Applied Animal Behaviour Science 131:53-62.

Slavik P, Illek J, Brix M, Musilova L, Rajmon R, Klabanova P, Jilek F (2009) Health Status of Beef Cows and their Calves in the Czech Republic. Acta Veterinaria Brno 78:47-56.

Steele M (2019) Performance and Behavioural Effects of Separating Dairy Cows and Their Calves at Birth. Veterinary Evidence 4:24.

Stehulova I, Lidfors L, Spinka M (2008) Response of dairy cows and calves to early separation: effect of calf age and visual and auditory contact after separation. Applied Animal Behaviour Science 110:144-165.

Stehulova I, Valnickova B, Sarova R, Spinka M (2017) Weaning reactions in beef cattle are adaptively adjusted to the state of the cow and the calf. Journal of Animal Science 95:1023-1029.

Stewart PH, Arave CW, Dias B (1992) The effect of observation on Holstein heifer's learning ability in a closed field maze. Journal of Animal Science 70:Suppl. 1, 155

Sutherland MA, Worth GM, Schütz KE, Stewart M (2014) Rearing substrate and space allowance influences locomotor play behaviour of dairy calves in an arena test. Applied Animal Behaviour Science 154:8-14.

Vaughan A (2014) Can cattle be trained to urinate and defecate in specific areas? An exploration of cattle's urination and defecation habits and some aspects of learning abilities. PhD Thesis, University of Saskatchewan, Saskatoon.

Van Reenen CG, O'Connell NE, Van der Werf JTN, Korte SM, Hopster H, Jones $R B$, Blokhuis HJ (2005) Responses of calves to acute stress: individual consistency and relations between behavioral and physiological measures. Physiology \& Behaviour 85:557-570.

Veissier I, Le Niendre P, Trillat G (1987) The influence of mother-young relationships on behavioral reactivity and learning in calves. Biology of Behaviour, Masson 12:222-238.

Veissier I, Le Neindre P (1992) Reactivity of Aubrac heifers exposed to a novel environment alone or in groups of four. Applied Animal Behaviour Science 33:11-15

Veissier I (1993) Observational learning in cattle. Applied Animal Behaviour Science 35:235-243.

Von Keyserlingk MAG, Rushen J, de Passillé AM, Weary DM (2009) Invited review: the welfare of dairy cattle-key concepts and the role of science. Journal of Dairy Science 92:4101-4111.

Wagenaar JPTM, Langhout J (2007) Practical implications of increasing 'natural living' through suckling systems in organic dairy calf rearing. NJAS Wageningen Journal of Life Sciences 54:375-386.

Wagner K, Barth K, Hillmann E, Palme R, Futschik A, Waiblinger S (2013) Mother rearing of dairy calves: reactions to isolation and to confrontation with an unfamiliar conspecific in a new environment. Applied Animal Behaviour Science 147:43-54.

Watts JM, Stookey JM (2000) Vocal behaviour in cattle: the animal's commentary on its biological processes and welfare. Applied Animal Behaviour Science 67:15-33.

Watts JM, Stookey JM (2001) The propensity of cattle to vocalise during handling and isolation is affected by phenotype. Applied Animal Behaviour Science 74:81-95.

Webb LE, van Reenen CG, Jensen MB, Schmitt O, Bokkers EAM (2015) Does temperament affect learning in calves? Applied Animal Behaviour Science 165:33-39.

Wechsler B, Lea SEG (2007) Adaptation by learning: Its significance for farm animal husbandry. Applied Animal Behaviour Science 108:197-214.

Wredle E, Rushen J, de Passillé AM, Munksgaard L (2004) Training cattle to approach a feed source in response to auditory signals. Canadian Journal of Animal Science 84:567-572. 